\title{
Female Leadership Capacity and Effectiveness: A Critical Analysis of the Literature on Higher Education in Saudi Arabia
}

\author{
Miznah O. Alomair ${ }^{1}$ \\ ${ }^{1}$ College of Educational Studies, Chapman University, Orange, California, USA \\ Correspondence: Miznah O. Alomair, College of Educational Studies, Chapman University, Orange, California \\ 92866, USA. Tel: 1-714-997-6815. E-mail: aloma109@mail.chapman.edu
}

Received: August 23, 2015

Accepted: September 10, 2015

Online Published: September 15, 2015

doi:10.5430/ijhe.v4n4p81

URL: http://dx.doi.org/10.5430/ijhe.v4n4p81

\begin{abstract}
In light of the progressive changes occurring in Saudi Arabia, developing female leadership capacity and effectiveness in the country's higher education is vital. This literature review examines the scholarship and research on female leadership in higher education in Saudi Arabia, describes the major barriers for female leaders, and provides a critique of the available literature regarding efforts in developing and sustaining female leadership capacity and effectiveness in Saudi Arabia's higher education. The literature review concludes by identifying major limitations and needs for research on this particular topic.
\end{abstract}

Keywords: Women, Leadership, Higher education, Leadership capacity, Leadership effectiveness, Saudi Arabia

\section{Introduction}

One the most significant topics of discussion across most fields is female leadership. With issues of gender inequality attracting researchers' attention for many years, it is becoming increasingly difficult to ignore the limited leadership roles and opportunities for women in higher education (Bonebright, Cottledge, \& Lonnquist, 2012; Haslam \& Ryan, 2008; Madsen, 2012a, 2012b; Madsen, Longman, \& Daniels, 2012; White, 2012). Despite the progress in higher education regarding female advancement, gender discrepancies are evident based on four particularly important findings. First, women in higher education are underrepresented in leadership positions (Bonebright et al., 2012; Chin, 2011; Lapovsky, 2014; Madsen, 2012a, 2012b; Madsen et al., 2012; Tessens, White, \& Web, 2011; White, 2012). In 2006, approximately 23\% of college presidents in American higher education were women, but the majority of them were at community colleges and small private universities (Bonebright et al., 2012; Chin, 2011; Madsen, 2012a, 2012b). However, most recent reports indicate that women represent $26 \%$ of college and university presidents (Cook, 2012; Lapovsky, 2014; White, 2013). While there is an increase of female leaders in higher education, progress remains slow (Lapovsky, 2014; Madsen, 2012b; White, 2013). The lack of women at the highest level of leadership in higher education has been attributed to the challenges women in academia are likely to face such as discouragements over career advancements, personal circumstances, and invisible rules within institutions (Cook, 2012; Lapovsky, 2014; Madsen, 2012b).

Second, women in higher education tend to hold lower academic ranking than men (Madsen, 2012a, 2012b; Schneider, Carden, Francisco, \& Jones, Jr., 2011). Although women account for $43.94 \%$ of faculty at American colleges and universities, only $26.81 \%$ of them hold the rank of professors. For example, $49.34 \%$ of assistant professors, $42.17 \%$ of associate professors, and only $29.12 \%$ of full professors are women. Whereas, men represent $50.66 \%$ of assistant professors, $57.82 \%$ of associate professors, and $70.88 \%$ of full professors (NCES, 2014).

Third, women are underrepresented as faculty at four-year private and public universities with $35.2 \%$ and $38.7 \%$ respectively (NCES, 2014). Yet, they account for $62.4 \%$ of faculty at community colleges (Madsen, 2012b; NCES, 2014; Schneider et al., 2011). Fourth, there has not been any progress in bridging the salary gap whereby women reportedly earn less than men. Although they earned $83 \%$ of their male colleagues' earnings four decades ago, female academics today earn $82 \%$ of what male academics earn (Madsen, 2012a, 2012b; NCES, 2014; Schneider et al., 2011).

The underrepresentation of women in academic and administrative leadership roles is a global phenomenon (Madsen, 2012a, 2012b; Pyke, 2013; Schneider et al., 2011; Tessens et al., 2011). Throughout 27 countries in the European Union, only $13 \%$ of higher education institutions are lead by women. Furthermore, female academics account for 
$16.5 \%$ of full-time university professors in the United Kingdom, and represent a little bit over $19 \%$ of full professors at Australian universities (Morley, 2013; Schneider et al., 2011; Tessens et al., 2011). In fact, the national average for female appointments to associate professor and full professor positions at Australian universities is approximately 27 percent (Pyke, 2013).

Across countries in the Middle East and North Africa (MENA), women hold 3.2\% of overall senior leadership positions (Pande \& Ford, 2011; Patel \& Buiting, 2013). Particularly in the Gulf Cooperation Council (GCC) countries- Bahrain, Kuwait, Oman, Qatar, Saudi Arabia, and the United Arab Emirates (UAE), they represent less than $1 \%$ of organizational leaders (Sperling, Marcati, \& Rennie, 2014). Despite gender-segregation policies applied in Saudi Arabia's higher education that offers opportunities for female leadership, women are underrepresented in leadership positions (Jamjoom \& Kelly, 2013). While over half of college students enrolled in Saudi Arabia's higher education institutions are females (Al Ankari, 2013), only 4\% of college and university presidents are women (Jamjoom \& Kelly, 2013; "Women in higher education," 2010).

Moreover, in spite of the fact that college enrollment, retention, and graduation rates are higher among females than males in GCC countries such as Saudi Arabia and the UAE (Hausman, Tyson, \& Zahidi, 2012), female academic professionals are underrepresented (Al Ankari, 2013; Al-Ohali \& Al-Mehrej, 2012; Indicators of the UAE Higher Education Sector, 2013; "Women in higher education," 2010). For instance, the 2010 data on female employment in Saudi Arabia's 68 higher education institutions indicated that less than $40 \%$ of faculty members were women with the majority holding lower academic ranks (Al-Ohali \& Al-Mehrej, 2012; Jamjoom \& Kelly, 2013). Similarly, data on UAE's 102 colleges and universities indicated that only $30.8 \%$ of faculty members are women (Indicators of the UAE Higher Education Sector, 2013).

Although gender inequality in academia is a wide spread phenomenon, there is an urgent need for female leadership in higher education (Chin, 2011; Madsen, 2012a, 2012b; White, 2012, 2013). With predictions of future turnover and retirement rates of university presidents and chancellors, there is a window of opportunity to promote and enhance gender equality for women in higher education (C’ordova, 2011; White, 2012). Female leaders provide unique perspectives and positive experiences, enhance institutional performance and scope of research, and bring about transformational change (Madsen, 2012a, 2012b). According to Diehl (2014), female leaders bring their interpersonal styles into leadership, are better able to foster inclusion, trust, empathy, and concern for others, and implement a transformational leadership style that is more future-oriented, participative, and democratic. Moreover, female leaders inspire young women by serving as role models and mentors for them (Diehl, 2014; Madsen, 2012a, 2012b).

To increase the number of women in higher education leadership positions, researchers (Madsen, 2012a, 2012b; White, 2013) stressed on the need to prepare female academics and administrators to successfully take on leadership roles. However, the available literature on women and leadership in academia tends to focus more on the challenges and barriers faced by female leaders and less on leadership development (Madsen, 2012a, 2012b). Thus, it is necessary to review the literature available on the development and sustainability of female leadership capacity and effectiveness in higher education.

\section{Framing the Review}

Throughout the past several years, Saudi Arabia's government has been implementing reform plans in order to diversify its source of revenue away from oil and reduce the unemployment rate of women in the country (Carey, 2012). With major reform efforts underway (Smith \& Abouammoh, 2013), higher education institutions in Saudi Arabia place minimal focus on developing female leadership capacity and effectiveness. Therefore, this literature review examines the need to expand upon female leadership capacity and effectiveness in Saudi Arabia's higher education.

To avoid any biases in the review process, it was necessary to gather studies that had been conducted by authors with diverse backgrounds such as gender, ethnicity, religion, nationality, race, and field of discipline. In addition, it was essential to reflect on each study by determining what it contributed to higher education in general, and to female leadership in particular.

Furthermore, it was vital that I consider my role as a reviewer in influencing the review process in three possible ways, my gender, my national origin, and my expectations on the findings. As a female and a Saudi national, I recognize that I bring my own set of biases. Thus, I approached the literature with an open mindset to consider different aspects of an idea and accept new or opposing perspectives on the topic (Stone, 2014). Doing so enabled me to think about the research and the method or style of reporting with unrestricted curiosity and skepticism, and with 
high levels of self-awareness on any predetermined ideas that can influence the review process.

Moreover, I utilized an analytical and reflective approach in critiquing the methodologies and findings used in research studies (Creswell, 2009). By engaging in critical analysis and reflection, I was able to recognize issues in higher education leadership, gain better insight and understanding of what has been informed and published on female leadership in Saudi Arabia's higher education, identify the gaps in the literature, and ascertain what is needed for further research.

The literature review begins by discussing the perspectives on the underrepresentation of female leaders in higher education. Then, it explains the current status of female leadership in the GCC states. Since this review aims to focus on female leadership in Saudi Arabia's higher education, it seems necessary to present a brief discussion on women and education in the country that analyzes the issue of gender segregation in education and its impact on female leadership. To conclude the review, an analysis is provided on the available literature regarding female leadership development in Saudi Arabia's higher education.

\section{Female Leadership in Higher Education}

A considerable amount of literature has been published on the advancement of women in leadership positions in higher education (Arini, Collings, Conner, McPherson, Midson, \& Wilson, 2011; Christman \& McClellan, 2008; Diehl, 2014; Kellerman \& Rhodes, 2014; Keohane, 2014; Madsen; 2012a, 2012b; Pyke, 2013; Tessens et al., 2011; Toma`s, Lavie, del Mar Duran, \& Guillman, 2010). These studies addressed the need to develop more female leaders in higher education, external factors that may affect their resilience, internal challenges produced by university cultures, as well as gender stereotypes and imbalances in leadership positions that continue to inhibit the efforts of gender equality. Throughout this section, I will review the literature that establishes a clear understanding of the underrepresentation of females in leadership positions in a higher education setting. In particular, I will discuss how the literature (a) presents barriers and obstacles that hinder leadership opportunities for women, and (b) describes attitudes towards women in leadership roles.

\subsection{Barriers and Obstacles that Hinder Leadership Opportunities for Women}

Researchers (Arini et al., 2011; Kellerman \& Rhodes, 2014; Keohane, 2014; Pyke, 2013; Tessens et al., 2011; Toma`s et al., 2010) have been able to identify actual or perceived barriers and obstacles to female advancement in higher education settings. Such barriers and obstacles are perceived as gender-based and function at social, organizational, and personal levels (Diehl, 2014). Drawing upon the previous work of Rhodes and Kellerman (2007) and of Kellerman and Rhodes (2012), their most recent research (Kellerman \& Rhodes, 2014) on women and leadership in higher education helped to explain the underrepresentation of female leaders. They highlighted unconscious bias, lack of confidence and fear of failure, in-group favoritism, and difficulty balancing the demands of family and work, as obstacles women in leadership roles tend to face. In helping to elucidate the concept of unconscious bias, the authors indicated that women lack presumption of competencies compared to men in which they assume the need to work twice as hard to be perceived as equal to their male colleagues. They accentuated the problem of in-group favoritism occurring in a traditionally male-dominant environment. With men overrepresented in leadership roles and in higher academic ranks, the authors stated that it increases loyalty and cooperation among them and results in female academics being marginalized and excluded from attaining similar provisions.

In the literature gathered (Arini et al., 2011; Kellerman \& Rhodes, 2014; Keohane, 2014; Pyke, 2013; Tessens et al., 2011; Toma`s et al., 2010), difficulty balancing the demands of family and work emerged as a recurrent barrier to female advancement in higher education. For example, Kellerman and Rhodes (2014) highlighted the disproportionate burdens in the home where women attend to family responsibilities more than their spouses. Thus, challenges arose with the demands of running an academic department or a complex organization.

In keeping with Kellerman and Rhodes's (2014) concept of disproportionate burdens, Toma`s et al. (2010) conducted a study on 18 female leaders across four universities in Spain. The findings revealed that female leaders had the greatest difficulty attending to the conflicting demands and commitments of family and career. Moreover, the authors claimed that the decisions female leaders made to take on leadership roles were associated with a specific time in their lives such as when their children were enrolled in school or had left home. Tessens and colleagues (2011) reported similar findings. They conducted a survey study that analyzed the career developmental needs of over 200 female leaders at two Australian universities. According to the results of the study, challenges faced by female leaders included excessive workload, difficulty balancing the demands of family and work, and the lack of professional support.

Drawing on the findings of Toma`s et al. (2010) and Tessens et al. (2011), Arini et al. (2011) conducted a research 
study to highlight the impact of formal and informal experiences female university leaders had on their professional development and advancement. They used the Critical Incident Technique as their method of narrative inquiry on 26 female leaders across eight universities in New Zealand. The Critical Incident Technique is "a form of interview research in which participants provide descriptive accounts of events that facilitated or hindered a particular aim" (Arini et al., 2011, p. 48). In describing the findings on what hindered women's advancement, Arini and colleagues indicated that family responsibilities and lack of encouragement and support from mentors were among the most reported factors. Clearly, balancing work with family responsibilities emerged as a common theme in research studies of female leaders in higher education.

In keeping with Kellerman and Rhodes's (2014) discussion on barriers to female career advancement, Keohane (2014) illustrated the factors that cause ambitious females to opt-out of leadership roles in higher education. She indicated that women find it difficult to combine family and home responsibilities with a demanding leadership position. The author pointed to the minimal support found in organizations that implement workplace policies such as quality daycare, flexible work schedule, and assistance for caretakers.

Pyke (2013) investigated reasons in which female academics opt-out of leadership roles or withdraw from seeking promotions in higher education. In her study, the author conducted in-depth semi-structured interviews with 24 culturally diverse female lecturers at an Australian university to explore factors that influence women to withdraw from seeking a promotion to a higher academic ranking. According to the findings, discouraging experiences and timing emerged as two main factors that discourage women to seek a promotion and advance their careers. The author described discouraging experiences to include negative organizational culture and hostile work environment. Similar to Tessens et al. (2011), Pyke presented the significant impact professional support and encouragement from mentors and colleagues have on aspiring female academics.

Moreover, Pyke (2013) described timing to refer to family responsibilities and changes in promotion policies. The author emphasized that without family responsibilities, aspiring female academics are able to commit to work demands. While the results seem to support previous studies, one question that needs to be asked, however, is whether the diverse cultural backgrounds of participants could have played a role in their own perception of what might influence their decision to withdraw from a promotion. According to the participants, they reported experiences of hostile work environment that may have been a result of racial and ethnic discrimination.

\subsection{Attitudes Towards Women in Leadership Roles}

Researchers (Kellerman \& Rhodes, 2014; Keohane, 2014; Toma`s et al., 2010) were able to identify gender stereotypes as a leading factor in shaping attitudes toward women in leadership roles, which hinder opportunities for career advancement. In Kellerman and Rhodes (2014), it is emphasized that females face a double bind and double standard due to prevailing gender stereotypes associated with leadership and masculinity. According to the authors, female leaders who are assertive can be perceived as lacking compassion or insensitive to the needs of others. Similarly, Keohane (2014) asserted that gender stereotypes act as roadblocks for women to be evaluated fairly on the basis of their accomplishments. She further explained that women are likely viewed as incompetent to make hard decisions as a result of associated gender stereotypes such as nurture, kindness, and sensitivity. In contrast, she argued, women who are competent in making hard decisions tend to be judged as harsh or unwomanly.

Toma's et al. (2010) offered similar findings in their study. One of the findings reported points to gender discrimination and stereotypes that are maintained in a male-dominant environment. The authors stressed that gender roles impose limitations on women and impact their ambition toward leadership. They also identified gender discrimination and stereotype practices to include unfair performance evaluations based on male standards, the undervalue of women's professional careers, and assumptions on women's lack of necessary qualities for leadership.

\section{Female Leadership in the GCC States}

In recent years, there has been an increasing amount of literature on women's limited career advancement in the Middle East, particularly in the GCC states (Al-Ahmadi, 2011; Elamin \& Omair, 2010; Kauser \& Tlaiss, 2011; Madsen, Kemp, \& Davis, 2014; Metcalfe, 2006, 2007, 2008, 2011; Sperling et al., 2014). These studies brought attention to context-specific factors that impede opportunities for women in the region to take on leadership roles. In this section, I first discuss the literature that examines social, cultural, and organizational factors in order to establish a clear understanding of the underrepresentation of female leaders in the GCC states. I then turn to research studies that identify the challenges and barriers facing female leaders in Saudi Arabia. 


\subsection{Social, Cultural, and Organizational Factors in the GCC}

Metcalfe's $(2006,2007,2008,2011)$ work contributed to the studies available on the status of female leaders in the Middle East. She identified factors that are instrumental in understanding the underrepresentation of women in leadership positions in GCC countries. Her early work $(2006,2007,2008)$ found cultural practices, lack of equal opportunities in organizations, and limited professional support and organizational services are barriers to the career advancement of women in the region. The author indicated that cultural practices such as defined gender roles and restrictions on interactions between men and women create gender-segregated workspaces and establish gender-based occupations. In turn, it sustains a traditional patriarchal organizational structure. Moreover, the author pointed to the limited professional support and organizational services available for women in regards to mentoring and training programs. She further explained that the lack of equal opportunities in organizations is predominantly a reflection of the biases in recruitment and selection processes. For example, job appointments in the GCC states are often based on individual and family networks rather than on qualifications and competencies (Metcalfe, 2007).

In her seminal work, Metcalfe $(2006,2007,2008)$ presented the idea of equal but different philosophy as a cause to the gender-based work hierarchies that define gender-specific occupations and promote gender-segregated work environments. While the author emphasized that gender-segregated organizations offer limited financial resources for training and development opportunities for women, she argued that gender segregation should not be defined as discriminatory work practices. Metcalfe $(2006,2007)$ suggested that it should be conceptualized as practices that respect and value women and their families.

An evaluation of the social and cultural barriers to women's empowerment and development in three GCC states, Bahrain, Saudi Arabia, and UAE, builds on the equal but different philosophy (Metcalfe, 2011). While the author recognized that Islamic law grants women the right to work and advance in their careers, she posited that cultural practices guide the interpretation of women's rights to work. Metcalfe presented what she refers to as the Islamic Gender Regime. Her concept is based on the biological differences between men and women that define their social roles. According to the concept, family responsibilities of men and women are viewed differently, but complementary. For instance, she explained that cultural processes define a woman's role in the family as a homemaker whereas a man's role in the family is to financially provide and protect them. Thus, justifying men's authority over women (Metcalfe, 2011). However, such an explanation tends to overlook the fact that such cultural and social processes exploit Islam's spirit and ideals to legitimize the defined submissive roles of Muslim women (Elamin \& Omair, 2010; Kauser \& Tlaiss, 2011).

In keeping with Metcalfe's $(2006,2007,2008)$ work on barriers to the career advancement of women in the Middle East, Kauser and Tlaiss (2011) provided a systematic literature review on social and cultural practices challenging Arab female leaders. Their review focused on the countries receiving most research attention such as Lebanon, Egypt, and the six GCC states. The authors addressed the patriarchal nature of organizations in the Arab region as an explanation to the existing traditional attitudes toward masculine traits associated with leadership. They asserted that gender role stereotypes are culturally constructed and reflective of the Arabic family context and social traditions. Furthermore, Kauser and Tlaiss's literature review highlighted organizational barriers to the career advancement of Arab female leaders such as exclusion from the organization's networks, absence of female role models and mentoring programs, minimal opportunities for training and development programs, and the lack of systemic performance evaluation and career planning processes.

In their study, Madsen et al. (2014) offered similar findings. By investigating the status of women in leadership positions in the six GCC states, the authors highlighted the impact cultural and social factors have on gender equality within organizations in the region. They reported on cultural practices, social and family pressures, policies, and business practices as overlapping factors that effect the career development of women in these countries.

An executive report conducted by Sperling et al. (2014) drew on the status of female leaders in the GCC states. The authors collected their data from responses to an online survey, interviews, and available public information on family businesses, private organizations, public organizations, and semi-governmental organizations throughout various fields in the GCC states. The online survey focused on barriers to female representation in leadership positions and strategies implemented to eliminate them. From the survey, the sample consisted of 555 male and female middle and senior managers in the region. Over half the sample $(75.49 \%)$ was male. To acquire a qualitative understanding of how they perceived and implemented gender diversity in their organizations, interviews were conducted on 50 chief or senior executives and board members of organizations in the region. Findings from the survey indicated that female and male participants perceived the biggest barriers to increasing the number of GCC women in leadership positions similarly. For instance, male and female participants together agreed that four factors 
were the biggest barriers to female leaders: 1) the double-burden syndrome; 2) lack of pro-family public policies and support services such as daycare; 3 ) family and social expectations that women will not work continuously; and 4) lack of appropriate infrastructure such as transportation and gender-segregated work spaces.

The findings of Sperling et al. (2014) highlighted major barriers to female leadership in the region. However, the research report presented serious weaknesses. It did not indicate the qualitative method used to analyze the data generated from the interviews. In addition, the sample was not representative of the general female population in the region. For example, female participants in the survey represented only $24.5 \%$ of the sample. With approximately $75 \%$ of the sample taken represented the men's perspective and is combined with women's responses without differentiation of the two genders, their perspective overshadows women's responses to the survey. Another weakness was evident in the lack of demographic information on participants. Since the research report included samples from six countries, Sperling and colleagues (2014) failed to provide detailed demographic characteristics such as nationality, age, educational background, degree attainment, marital status, and years of experience on all participants. Their method approach presented additional gaps such as the reliability and validity of the survey used, in addition to the format and schedule of the interviews. Thus, the findings of this research report should be interpreted with considerable caution, as they are regarded as suggestive and do not offer empirical evidence.

\subsection{Challenges and Barriers Facing Female Leaders in Saudi Arabia}

One of the few studies conducted on female leaders in Saudi Arabia examined the challenges and barriers for female advancement in the workplace. To identify the most salient challenges facing female leaders in Saudi Arabia, Al-Ahmadi (2011) used a survey questionnaire designed to measure five leadership challenges: structural, cultural, lack of empowerment, personal, and lack of resources. The initial sample in this study consisted of 300 randomly selected female leaders who attended leadership development workshops at the Institute of Public Administration in Saudi Arabia. Out of the total questionnaires distributed only 162 were completed, representing a 54\% response rate. According to the results, structural challenges such as centralized decision-making processes, exclusion from strategic planning, and limited authority were the most reported by the participants. The results further showed the lack of resources regarding restricted financial authority and inadequate buildings and facilities were ranked in second place among the leadership challenges. In addition, participants identified the lack of empowerment as a significant obstacle to female leadership in Saudi Arabia. Al-Ahmadi claimed that the country's Saudization process and the absence of leadership development training has resulted in women taking on leadership positions in public and private organizations without building the necessary and appropriate leadership skills and competencies. The author emphasized that the lack of mentoring opportunities offered to Saudi women is due to factors such as the confined experiences of female leaders in the country, absence of female leaders as role models, and segregated work environments that prevent equal opportunities for leadership development.

The most striking results to emerge from Al-Ahmadi's (2011) study were that family and social pressures, fear of responsibility, difficulty balancing between family and work demands, and gender stereotypes were reported as the least of barriers to female career advancement. The results contradicted previous findings (Kauser \& Tlaiss, 2011; Metcalfe, 2007, 2008, 2011) on Arab women struggling to balance family commitments with work demands. Al-Ahmadi (2011) posited that the findings confirm not only a shift in attitudes and perceptions toward Saudi women's role in society, but also a change in the country's policies that advocate for female empowerment.

Building upon socio-cultural factors and gender inequality in organizations, a number of studies identified attitudes toward Arab women in the workplace as a barrier to career advancement (Kauser \& Tlaiss, 2011; Metcalfe, 2007, 2008, 2011; Mostafa, 2005). In keeping with those findings, Elamin and Omair's (2010) study provided useful findings to help establish human resources policies that address barriers to career advancement of Saudi women. They assessed the attitudes of Saudi men regarding Saudi women in the workplace. The authors used two variables, employment skepticism and traditional role preferences, to assess attitudes and expectations. Participants were randomly selected from the Eastern province in Saudi Arabia. Initially, the sample consisted of 500 Saudi men of whom 354 completed the self-administered questionnaire. However, only 301 questionnaires were used for analysis. According to the demographic variables of the study, more than half of the participants were married, employed, and college educated. Moreover, participants aged 18 to 25 were the largest of the age groups.

The findings of the study (Elamin \& Omair, 2010) demonstrated that Saudi men present traditional attitudes toward Saudi women in the workplace. The authors indicated that the participants presented strongly held beliefs on gender stereotypes that view men as capable of taking on leadership roles, whereas women were prescribed to domestic and child rearing responsibilities. In addition, the findings revealed that single, unemployed, and college educated male participants reported less traditional attitudes towards Saudi women in the workplace. To explain a particular finding 
in which younger participants, aged between 18 and 25, presented less traditional attitudes, Elamin and Omair argued that it is an important predictor of future generations' attitudes regarding female employment in Saudi Arabia.

\section{Women and Higher Education in Saudi Arabia}

During the past decade, much more information has become available on women and education in Saudi Arabia (Hamdan, 2005; Jamjoom \& Kelly, 2013; Parveen, 2014; Stefani, 2014; Taleb, 2010). However, much of the research up to now has been descriptive of the current state of Saudi women and education than empirical (Hamdan, 2005; Jamjoom \& Kelly, 2013; Parveen, 2014). In this section, I will shed light on the available literature describing the current state of women and higher education in Saudi Arabia. Furthermore, this section will discuss leadership issues that are embedded in Saudi Arabia's institutions of higher education.

To analyze women's education in Saudi Arabia, Hamdan (2005) reflected on the social, economic, and political conditions in the country that provide a clear understanding of women's role in society. In addition, her work explored the challenges and achievements in women's education. She posited that cultural practices, rather than the Islamic religion, have denied women equality. Practices and customs in Muslim societies, such as restrictions on women's career choices and educational interests, are viewed as Islamic even though Islamic texts do not support such views. Referring to Islam's history, the author provided ample amount of examples that highlight Muslim women's advancement in political, economic, scientific, and social fields. By way of illustration, Hamdan (2005) showed how Prophet Mohammed's first wife Khadijah was a prominent businesswoman; his daughter Fatima was politically active, and his granddaughter Sukienah was known as a mathematician. As a result, the author refuted the claims of religious conservatives on women and education by presenting strong examples from the Qur'an and the teachings of Prophet Mohammed that stress on women's education in all fields.

In her explorative research, Hamdan (2005) indicated that gender segregation, while perceived as a barrier to women's education, provides Saudi women with leadership opportunities. In contrast, Jamjoom and Kelly (2013) illuminated on gender segregation in higher education as a barrier to female advancement. They argued that in gender-segregated campuses, conservative male academic leaders do not engage in direct lines of communication with female academics. The authors emphasized that female deans and faculty members, in turn, are excluded from decision-making processes, thus highlighting structural challenges that maintain gender hierarchies in educational institutions.

Hamdan's (2005) analysis on women's education demonstrated that gender inequalities in Saudi Arabia are not only socially constructed but also institutionalized within the country's education system in which they are impossible to eradicate without collective and political effort. Furthermore, the author pointed to the challenges faced by Saudi women as a result of traditional attitudes toward their participation in leadership positions. However, Parveen (2014) captured the most recent progress in Saudi women's career advancement in which they have demonstrated their ability to uphold leadership positions in private and public sectors. The author highlighted Saudi women's political involvement in the Shura Council, an advisory council to the country's King, as a historic milestone. Drawing attention to the growing number of Saudi female leaders in all fields, she claimed they have become role models for aspiring young leaders and shifted society's attitudes toward female leadership.

While the available literature previously discussed (Hamdan, 2005; Jamjoom \& Kelly, 2013; Parveen, 2014) on Saudi women and education provided insight into the complex social and cultural challenges, it failed to address the needs to prepare women in higher education for leadership roles. Hamdan's (2005) work focused on the debate between feminist and religious scholars' perspectives on women's roles in society and as leaders. Meanwhile, Jamjoom and Kelly (2013) failed to offer recommendations that are forward-driven and strategically aligned to trends in global education. Lastly, a major weakness in Parveen's (2014) work is the findings of the research. Her work, while informative, resembled a report that does not acknowledge leadership issues in Saudi Arabia's higher education, such as bureaucracy and centralization.

\section{Developing and Sustaining Female Leadership in Higher Education}

Due to the changes occurring in the GCC states regarding women, it is necessary that I explore the efforts of and outcome for female leadership development and training within higher education settings. Since 2010, the Saudi government recognized the need to invest in the development of men and women's leadership capacity as a significant strategy toward progress ("Women in higher education," 2010). According to the literature (Hamdan, 2005; Islam, 2014; Khan \& Varshney, 2013; Parveen, 2014; "Women in higher education," 2010), Saudi women are increasingly pursuing graduate and postgraduate degrees and succeeding professionally. While gender segregated college and university campuses have been noted to provide Saudi females with leadership opportunities, limited 
scholarly work can be found on Saudi women's leadership development in higher education (Stefani, 2014; Taleb, 2010). Therefore, this section will discuss and analyze research that focus on female leadership development in Saudi Arabia's higher education.

In a case study that illustrated the need for building leadership capacity effectiveness at an all-women public university in Saudi Arabia, Stefani (2014) reported on the complexities involved in such an academic environment and the strategies used to develop female academic leaders during a 6-month training project. The report described the university as one of the largest universities in the world with approximately 40,000 female students, 12,000 female employees, and over 20 colleges. Only recently launched from an amalgamation of colleges, the university faces transitional challenges as it moves from a college culture to a scholarly one. Stefani (2014) classified the leadership challenges in this case to include the following: (a) misperceptions and misunderstandings over the essence of leadership, (b) evident social division between tradition and progression, (c) absence of systematic processes and procedures, (d) complex hierarchal organizational structure that maintains bureaucracy and centralization, and (e) poorly-communicated vision and ill-defined strategic plan. Using Kouzes and Posner's (2012) transformational leadership model, participants developed and exercised their leadership capacity through uplifting leadership strategies such as mentoring and coaching, empowerment, establishing trust, and transparency. This framework, Stefani (2014) maintained, is an effective approach to leadership development that is collaborative, inspirational, visionary, and promotes authenticity in a complex academic culture.

Stefani (2014) indicated that while the leadership development project had a positive effect on the morale of participants, issues emerged from the leadership development training. The author posited that participants lacked continuous practice, minimal systemic changes were recognized, and challenges in changing the status quo occurred. Based on the circumstances and conditions provided, Stefani found that sustaining leadership capacity and effectiveness requires female leaders to lead by example, implement a value-driven leadership approach, engage with others, inspire, encourage, and recognize performances. Clearly, the case study provided valuable insight into a complex hierarchal structure in an academic organization. However, one of the weaknesses in this study is that the author offered no additional information on the participants such as age, work experience, and area of specialization. It is safe to indicate that Stefani's (2014) study would have contributed valuable information to the literature had she included an investigation of the relationship between demographic variables and organizational commitment of female academic leaders in a Saudi Arabian public university.

Another weakness recognized in Stefani's (2014) study is that no information was provided in regards to the leadership development program such as the number of training hours per week and the drop out rate of participants from the program. In addition, the author failed to integrate empirical results from program evaluations. The findings might have been far more useful had the author included data from interviews or a self-administered questionnaire distributed to participants. By gathering empirical data on challenges and outcomes to the leadership development training, Stefani would have been able to address recommendations for building female leadership capacity and effectiveness in Saudi Arabia's higher education.

In a qualitative study on female leadership style in academic institutions, Taleb (2010) used a case study approach to gain an understanding of the leadership styles implemented at an all-women's college in Saudi Arabia. The author conducted in-depth semi-structured interviews with seven female leaders at the college to investigate their perception on what female leadership effectiveness in Saudi Arabia's higher education entails, and on their own leadership styles. The study sample, according to Taleb, was selected on the basis that participants were leading their employees toward the vision and goals of the college and of their academic or administrative departments. Based on the findings, the participants indicated that effective leaders inspire a shared vision, lead by example, foster teamwork and collaboration, engage with others, ensure transparency, and are committed, confident, and trustworthy. Further findings demonstrated that the participants adopted Bass and Reggio's (2006) transformational leadership style that emphasizes on idealized influence (leading by example and dedication), individualized consideration (support, encouragement, and coaching), and inspirational motivation (shared vision).

The results of Taleb's (2010) study indicated that effective leadership is adopted in a Saudi Arabian academic institution. An implication of this is the possibility of developing and sustaining transformational leadership behavior at colleges and universities in Saudi Arabia. While Taleb (2010) recognized the limitation of her study whereby the findings cannot be generalized due to sampling issues, one major drawback was noted. The author justified the use of a semi-structured approach for the study by indicating that it was beneficial to implement an in-depth interview process on senior managers and leaders who present different backgrounds and views on leadership. However, Taleb failed to fully acknowledge the possible influence participants' diverse backgrounds could have had on the outcome 
of the study. Although the author pointed to transformational leadership's feminine qualities such as care, intuition, and self-awareness as correlated factors to the participants' effective leadership style, their own culture or surrounding environment might have influenced their perception regarding effective leadership.

\section{Limitations}

I have discussed the complex social and cultural factors involved in female leadership in higher education. However, this literature review has been limited in a number of ways. First, minimal research was available on female leadership in Saudi Arabia. For that reason, this review included studies that address women and leadership in the GCC states. Second, due to scarce knowledge on the topic, this review was unable to analyze female leadership in Saudi Arabia's higher education. The review relied on information pertaining to female leadership in general. Third, the research to date seemed to focus on improving Saudi higher education in regards to curricular reform, quality of teaching and learning, student engagement, and faculty development (Alnasser \& Dow, 2013; Alsudairi, 2012; Alwasal \& Alhadlaq, 2012; Al-Ghamdi \& Tight, 2013; Ismail \& Hassan, 2012). Fourth, the quality of data collection and information provided in the referenced work pertaining to higher education in Saudi Arabia can be criticized as insufficient. The current system of data collection and analysis is neither updated nor comprehensive. Finally, there are limited publications regarding academic leadership outcomes, female college students, and female administrators in Saudi Arabia's higher education (Jamjoom \& Kelly, 2013; Smith \& Abouammoh, 2013).

\section{Conclusion}

The primary purpose in this review has been to examine the scholarship and research on female leadership in Saudi Arabia's higher education. The review sought to determine the reasons for the underrepresentation of female leaders in higher education by identifying the barriers and challenges encountered. It aimed to address the barriers to female leadership opportunities and overall career advancement in the GCC states. The review intended to present the current state of female leaders in higher education and discuss leadership issues that are embedded in Saudi Arabia's institutions of higher education. Moreover, the literature was able to identify the needs for female leadership development programs in Saudi Arabia's higher education.

According to much of the literature, developing the capacity and competency of female leaders in higher education is needed and necessary to minimize gender disparities in academia. Several conclusions and recommendations can be drawn from this literature review on female leadership in academia. First, the underrepresentation of female leaders in higher education is a global phenomenon. The perceptions regarding the underrepresentation of female leaders in higher education were presented in similar findings across different geographical contexts. These findings identified difficulty balancing family responsibilities with work demands, organizational factors, and gender stereotypes as major roadblocks for females seeking leadership opportunities in higher education, and an explanations to the their overall underrepresentation as academic leaders. It was also shown that cultural and social practices in the form of defined gender roles and stereotypes, as well as organizational barriers in the form of bureaucracy and gender inequality are major obstacles faced by female leaders in the GCC states. While much has been informed on the challenges to female career advancement, it is necessary to assess the degree in which these factors continue to hinder female leadership opportunities. In turn, it can help generate effective solutions that will increase the number of female leaders in the region.

Second, with regards to female leadership in the GCC states, it has been argued that gender-segregation may be a barrier to female career advancement in the region. On one hand, researchers indicated that gender-segregated work environments might limit opportunities for gender equality, sustain patriarchal structures, and maintain traditional attitudes regarding female advancement in the work place. On the other hand, researchers claimed gender-segregated organizations are able to provide females with leadership opportunities. Further research would be helpful to examine the impact of gender-segregated work environments in different cultural settings on female leadership opportunities.

Third, developing female leadership in Saudi Arabia is a significant outcome from this literature. Saudi women are gradually being empowered in order to fully participate and contribute to the progression and modernization of the country. With college enrollment rates are higher in females than in males, it provides a clear picture of the prospective needs for female career advancement in the country. For this reason, female leadership development should be extended to college students that will equip them with the capacity and competencies needed for career advancement.

Fourth, even though scarce amount of literature is available on leadership in Saudi Arabia's higher education, it is evident that the development and sustainability of female leadership capacity and effectiveness will require the 
implementation of a transformational leadership framework. The use of this framework has been deemed successful in higher education settings, and identified as most effective in carrying out social change.

Finally, the need for empirically based studies on academic leadership in Saudi Arabia's higher education is vital to the sustainability of effective leadership. Thus, researchers should engage in scholarly activities that will generate implications and recommendations for female leaders, as well as meaningful research in this area.

\section{References}

Al Ankari, K. M. (2013). Foreword. In P. Maassen \& J. Muller (Series Eds.), Higher education dynamics: Volume 40. Higher education in Saudi Arabia: Achievements, challenges and opportunities (pp. v-vi). http://dx.doi.org/10.1007/978-94-007-6321-0

Alnasser, S. A., \& Dow, K. L. (2013). Delivering high-quality teaching and learning for university students in Saudi Arabia. In P. Maassen \& J. Muller (Series Eds.), Higher education dynamics: Volume 40. Higher education in Saudi Arabia: Achievements, challenges and opportunities (pp. 49-60). http://dx.doi.org/10.1007/978-94007-6321-0_5

Alsudairi, M. A. T. (2012). An effective model for the professional development of Middle Eastern faculty. In J. E. Groccia, M. A. T. Alsudairi, \& W. Buskist (Eds.), Handbook of college and university teaching: A global perspective (pp.143-153). Thousand Oaks, CA.: Sage Publications, Inc. http://dx.doi.org/10.4135/9781412996891.n10

Alwasal, S. H., \& Alhadlaq, S. M. (2012). Preparing Middle Eastern students for the future: Saudi Arabia as a case study. In J. E. Groccia, M. A. T. Alsudairi, \& W. Buskist (Eds.), Handbook of college and university teaching: A global perspective (pp. 77-90). Thousand Oaks, CA.: Sage Publications, Inc. http://dx.doi.org/10.4135/9781412996891.n6

Al-Ahmadi, H. (2011). Challenges facing women leaders in Saudi Arabia. Human Resource Development International, 14(2), 149-166. http://dx.doi.org/10.1080/13678868.2011.558311

Al-Ghamdi, S., \& Tight, M. (2013). Selecting and developing high quality academic staff. In P. Maassen \& J. Muller (Series Eds.), Higher education dynamics: Volume 40. Higher education in Saudi Arabia: Achievements, challenges and opportunities (pp. 83-93). http://dx.doi.org/10.1007/978-94007-6321-0_8

Al-Ohali, M., \& Al-Mehrej, H. (2012). Faculty salary and remuneration in the Kingdom of Saudi Arabia. In P. G. Altbach, L. Reisberg, M. Yudkevich, G. Androushchak, \& I. F. Pacheco (Eds.), Paying the professoriate: A global comparison of compensation and contracts (pp. 278-287). New York, NY: Taylor \& Francis.

Arini, Collings, S., Conner, L., McPherson, K., Midson, B., \& Wilson, C. (2011). Learning to be leaders in higher education: What helps or hinders women's advancement as leaders in universities. Educational Management Administration and Leadership, 39, 44-62. http://dx.doi.org/10.1177/1741143210383896

Bass, B. M., \& Riggio, R. E. (2006). Introduction. Transformational Leadership (2 ${ }^{\text {nd }}$ ed., pp. 1-18). Mahwah, NJ: Lawrence Erlbaum Associates, Inc.

Bonebright, D. A., Cottledge, A. D., \& Lonnquist, P. (2012). Developing women leaders on campus: A human resources-women's center partnership at university of Minnesota. Advances in Developing Human Resources, 14(1), 79-95. http://dx.doi.org/10.1177/1523422311429733

Carey, G. (2012, December 29). Saudi Arabia boosts spending goal by fifth in record budget. Bloomberg. Retrieved from http://www.bloomberg.com/news/2012-12-29/saudi-arabia-boosts-2013-spending-in-record-budget-state-tv.html

Chin, J. L. (2011). Women and leadership: Transforming visions and current contexts. Forum on Public Policy Online, 2011(2). Retrieved from http://eric.ed.gov/?id=EJ944204

Christman, D., \& McClellan, R. (2008). "Living on barbed wire": Reslient women administrators in educational leadership programs. Education Administration Quarterly, 44(1), 3-29. http://dx.doi.org/10.1177/0013161X07309744

Cook, B. J. (2012). The American college president study: Key findings and takeaways. American Council on Education: Leadership and Advocacy. Retrieved from http://www.acenet.edu/the-presidency/columns-and-features/Pages/The-American-College-President-Study.aspx 
Co 'rdova, D. (2011). Moving the needle on women's leadership. On Campus with Women, 40(1). Association of American Colleges and Universities. Retrieved from http://archive.aacu.org/ocww/volume40_1/data.cfm

Creswell, J. W. (2009). The use of theory. Research Design: Qualitative, Quantitative, and Mixed Method Approaches ( $3^{\text {rd }}$ ed.). Thousand Oaks, CA: Sage Publications, Inc.

Diehl, A. B. (2014). Approaches of women leaders in higher education: Navigating adversity, barriers, and obstacles. In F. Ngunjiri, K. A. Longman, \& S. R. Madsen (Series Eds.), Women and leadership in higher education. A volume in women and leadership: Research, theory, and practice (pp. 135-151). Charlotte, NC:Information Age Publishing, Inc.

Elamin, A. M., \& Omair, K. (2010). Males' attitudes towards working females in Saudi Arabia. Personal Review, 39(6), 746-766. http://dx.doi.org/10.1108/00483481011075594

Hamdan, A. (2005). Women and education in Saudi Arabia: Challenges and achievements. International Education Journal, 6(1), 42-64. Retrieved from http://files.eric.ed.gov/fulltext/EJ854954.pdf

Haslam, S. A., \& Ryan, M. K. (2008). The road to the glass cliff: Differences in the perceived suitability of men and women for leadership positions in succeeding and failing organizations. The Leadership Quarterly, 19, 530-546. doi:10.1016/j.lea.qua.2008.07.011

Hausman, R., Tyson, L. D., \& Zahidi, S. (2012). The global gender gap report 2012. World Economic Forum. Retrieved from http://www3.weforum.org/docs/WEF_GenderGap_Report_2012.pdf

Indicators of the UAE higher education sector: International comparison. (2013). Center for Higher Education Data and Statistics (CHEDS). Ministry of Higher Education Scientific Research, United Arab Emirates. Retrieved from http://www.cheds.ae/Reports/main.doc

Islam, S. I. (2014). Saudi women: Opportunities and challenges in science and technology. Education Journal, 3(2), 71-78. http://dx.doi.org/10.11648/j.edu.20140302.15

Ismail, E. A., \& Hassan, M. M. (2012). Cultural contexts and curricular design in Saudi Arabia and other Middle Eastern nations. In J. E. Groccia, M. A. T. Alsudairi, \& W. Buskist (Eds.), Handbook of college and university teaching: A global perspective (pp. 279-292). Thousand Oaks, CA.: Sage Publications, Inc. http://dx.doi.org/10.4135/9781412996891.n19

Jamjoom, F. B., \& Kelly, P. (2013). Higher education for women in the Kingdom of Saudi Arabia. In P. Maassen \& J. Muller (Series Eds.), Higher education dynamics: Volume 40. Higher education in Saudi Arabia: Achievements, challenges and opportunities (pp. 117-125). http://dx.doi.org/10.1007/978-94-007-6321-0_11

Kauser, S., \& Tlaiss, H. (2011). Middle Eastern women manager: Participation, barriers, and future prospects. Journal of International Business Economy, 12(1), 35-56. Retrieved from https://www.escholar.manchester.ac.uk/uk-ac-man-scw:126198

Kellerman, B., \& Rhode, D. L. (2012). Viable options: Rethinking women and leadership. In W. E. Rosenbach, R. L. Taylor, \& M. A. Youndt (Eds.), Contemporary Issues in Leadership ( $7^{\text {th }}$ ed., pp. 135-145). Boulder, CO: Westview Press.

Kellerman, B., \& Rhodes, D. L. (2014). Women at the top: The pipeline reconsidered. In F. Ngunjiri, K. A. Longman, \& S. R. Madsen (Series Eds.), Women and leadership in higher education. A volume in women and leadership: Research, theory, and practice (pp. 23-39). Charlotte, NC: Information Age Publishing, Inc.

Keohane, N. O. (2014). Leadership out front and behind the scenes: Young women's ambitions for leadership today. In F. Ngunjiri, K. A. Longman, \& S. R. Madsen (Series Eds.), Women and leadership in higher education. A volume in women and leadership: Research, theory, and practice (pp. 41-55). Charlotte, NC: Information Age Publishing, Inc.

Khan, S. A., \& Varshney, D. (2013). Transformational leadership in the Saudi Arabian cultural context: Prospects and challenges. In J. Rajasekar and L-S Beh (Eds.), Culture and gender in leadership: Perspectives from the Middle East and Asia, (pp. 200-227). United Kingdom: Palgrave Macmillan. http://dx.doi.org/10.1057/9781137311573.0017

Kouzes, J., \& Posner, B. (2012). The leadership challenge: How to make extraordinary things happen in organizations. San Francisco, CA: A Wiley Brand. 
Lapovsky, L. (2014, April 13). Why so few women college presidents? Forbes. Retrieved from http://www.forbes.com/sites/lucielapovsky/2014/04/13/why-so-few-women-college-presidents/

Madsen, S. R. (2012a). Women and leadership in higher education: Learning and advancement in leadership programs. Advances in Developing Human Resources, 14(1), 3-10. http://dx.doi.org/10.1177/1523422311429668

Madsen, S. R. (2012b). Women and leadership in higher education: Current realities, challenges, and future directions. Advances in Developing Human Resources, 14(2), 131-139. http://dx.doi.org/10.1177/1523422311436299

Madsen, S. R., Kemp, L., \& Davis, J. (2014, February). Women in business leadership: A comparative study of countries in the Gulf Arab states. Paper presented at the Academy of Human Resource Development International Conference in the Americas, Houston, TX. Retrieved from http://works.bepress.com/susan_madsen/209/

Madsen, S. R., Longman, K. A., \& Daniels, J. R. (2012). Women's leadership development in higher education: Conclusions and implications for HRD. Advances in Developing Human Resources, 14(1), 113-128. http://dx.doi.org/10.1177/1523422311429734

Metcalfe, B. D. (2006). Exploring cultural dimensions of gender and management in the Middle East. Thunderbird International Business Review, 48(1), 93-107. http://dx.doi.org/10.1002/tie.20087

Metcalfe, B. D. (2007). Gender and human resource management in the Middle East. International Journal of Human Resource Management, 18(1), 54-74. http://dx.doi.org/10.1080/09585190601068292

Metcalfe, B. D. (2008). Women, management and globalization in the Middle East. Journal of Business Ethics, 83, 85-100. http://dx.doi.org/10.1007/s10551-007-9654-3

Metcalfe, B. D. (2011). Women, empowerment and development in Arab Gulf states: A critical appraisal of governance, culture and national human resource development (HRD) frameworks. Human Resource Development International, 14(2), 131-148. http://dx.doi.org/10.1080/13678868.2011.558310

Ministry of Higher Education, Deputyship for Planning and Information, General Department for Planning and Statistics. (2010). Women in higher education: Saudi initiatives and achievements (L.D. No. 1431/4394). Retrieved

from http://www.mohe.gov.sa/ar/Ministry/Deputy-Ministry-for-Planning-and-Information-affairs/The-General-Admi nistration-of-Planning/Documents/women_in_higher_edu.pdf

Morley, L. (2013). The rules of the game: Women and the leaderist turn in higher education. Gender and Education, 25(1), 116-131. http://dx.doi.org/10.1080/09540253.2012.740888

Mostafa, M. M. (2005). Attitudes towards women managers in the United Arab Emirates. Journal of Managerial Psychology, 20(6), 522-540. http://dx.doi.org/10.1108/02683940510615451

National Center for Education Statistics (2014). The Condition of Education 2014 (NCES 2014-083). Washington, D.C.: U.S. Department of Education. Retrieved http://nces.ed.gov/programs/digest/d13/tables/dt13_316.80.asp

Pande, R., \& Ford, D. (2011). Gender quotas and female leadership: A review. Washington, D.C.: World Bank. Retrieved from http://www.hks.harvard.edu/fs/rpande/papers/Gender \%20Quotas\%20-\%20April\%202011.pdf

Parveen, M. (2014). Saudi feminization: Dynamical phases of Saudi women in the field of education and employment. Journal of American Science, 10(1), 52-66. Retrieved from http://www.jofamericanscience.org

Patel, G., \& Buiting, S. (2013). Gender differences in leadership styles and the impact within corporate boards. The Commonwealth Secretariat, Social Transformation Programs Division. Retrieved from http://www.cpahq.org/cpahq/cpadocs/Genderdiffe.pdf

Pyke, J. (2013). Women, choices and promotion or why women are still a minority in the professoriate. Journal of Higher Education Policy and Management, 35(4), 444-454. http://dx.doi.org/10.1080/1360080X.2013.812179

Rhodes, D. L., \& Kellerman, B. (2007). Women and leadership: The state of play. In B. Kellerman \& D. L. Rhodes (Eds.), Women and leadership: The state of play and strategies for change (pp. 1-62). San Francisco, CA: John Wiley \& Sons, Inc. 
Schneider, B. Z., Carden, W., Francisco, A., \& Jones, T. O. Jr. (2011). Women "opting out" of academia: At what cost? Forum on Public Policy Online, 2011(2). Retrieved from http://eric.ed.gov/?id=EJ944197

Smith, L., \& Abouammoh, A. (Eds.). (2013). Challenges and opportunities for higher education in Saudi Arabia: An exploratory focus group. In P. Maassen \& J. Muller (Series Eds.), Higher education dynamics: Volume 40. Higher education in Saudi Arabia: Achievements, challenges and opportunities (pp. 167-190). http://dx.doi.org/10.1007/978-94-007-6321-0_16

Sperling, J., Marcati, C., \& Rennie, M. (2014). GCC women in leadership- from the first to the norm: Unlocking women's potential to enhance organizational effectiveness in the Gulf Cooperation Council (GCC) states. Women Matter 2014. McKinsey \& Company. Retrieved from http://www.mckinsey.com/global_locations/europe_and_middleeast/middle_east/en/gcc_women_in_leadership

Stefani, L. (2014, November). Beyond the abaya: A leadership development case from Saudi Arabia. Paper presented at the Sixteenth Annual International Leadership Association Global Conference, San Diego, CA. Abstract retrieved from http://www.ila-net.org/Conferences/Past/index.htm

Stone, M. (2014). Critical thinking: How do you own it? Own Your Education!: A Student's Guide to Greater Success in School and Life, pp.75- 94. Upper Saddle River, NJ: Pearson Education, Inc.

Taleb, H. M. (2010). Gender and leadership styles in single-sex academic institutions. International Journal of Educational Management, 24(4), 287-302. http://dx.doi.org/10.1180/09513541011045236

Tessens, L., White, K., \& Web, C. (2011). Senior women in higher education institutions: Perceived development needs and support. Journal of Higher Education Policy and Management, 33(6), 653-665. http://dx.doi.org/10.1080/1360080X.2011.621191

Toma`s, M., Lavie, J. M., del Mar Duran, M., \& Guillamon, C. (2010). Women in academic administration at the university. Educational Management Administration and Leadership, 38(4), 487-498. http://dx.doi.org/10.1177/1741143210368266

White, J. S. (2012). HERS institutes: Curriculum for advancing women leaders in higher education. Advances in Developing Human Resources, 14(1), 11-27. http://dx.doi.org/10.1177/1523422311429732

White, J. S. (2013). HERS at forty: Shaping a new vision of women's (and men's) liberation. On Campus with Women, 41(2-3). Association of American Colleges and Universities. Retrieved from http://archive.aacu.org/ocww/volume41_2/feature.cfm?section=2 